\title{
Studies in Intracranial Stenting: We Must Not Retire from the Game of Science
}

\author{
J. Fiehler
}

Published online: 1 November 2014

(C) Springer-Verlag Berlin Heidelberg 2014

\begin{abstract}
The game of science is, in principle, without end. He who decides one day that scientific statements do not call for any further test, and that they can be regarded as finally verified, retires from the game... Those among us who are unwilling to expose their ideas to the hazard of refutation do not take part in the scientific game.

Karl Popper, "The Logic of Scientific Discovery” (1934)
\end{abstract}

The Federal Joint Committee of Germany commissioned the German Institute for Quality and Efficiency in Health Care (IQWiG) to prepare a "rapid report" on intracranial stenting that was released to the public on 9 October 2014. The report concludes " ... the risk of having another stroke is higher if patients ... not only receive clot-inhibiting drugs, but also have ... stents inserted. However, studies have provided no hint of a benefit from stenting..." [1]. This report is the result of a strictly pre-defined literature review done by independent scientists, and its conclusions mainly rest on the results of the Stenting and Aggressive Medical Management for Preventing Recurrent Stroke in Intracranial Stenosis (SAMMPRIS) study [2,3]. The data as such cannot be questioned. However, the interpretation of the results can be, and even more so, the conclusions, drawn from the data. They do not apply to the specific patient group that is typically treated with intracranial stenting in most German centers.

In an unparalleled swift concerted action, the German societies of Neurology (DGN) and Neuroradiology (DGNR), the German Stroke Society (DSG), and the German Profes-

J. Fiehler $(\bowtie)$

Klinik und Poliklinik für Neuroradiologische Diagnostik und Intervention, Universitätsklinikum Hamburg-Eppendorf,

Hamburg, Deutschland

e-mail: fiehler@uke.uni-hamburg.de sional Association of Neuroradiologists (BDNR) responded with an opinion paper that was released on 11 October 2014 and that also can be found within the Societies' Communications in this issue of Clinical Neuroradiology. All four societies agreed that intracranial stenting is still needed for patients with acute artery occlusions, patients with hemodynamic infarct patterns, and patients with recurrent symptoms under optimal medical therapy.

Early data of the SAMMPRIS study have been published in 2011 already [2]; the long-term-results were published earlier this year [3]: during a median follow-up of 32.4 months, $34 / 227(15 \%)$ of patients in the medical group and $52 / 224(23 \%)$ of patients in the stenting group had a primary end point event (stroke or death within 30 days after enrollment or after a revascularization procedure for the qualifying lesion during the follow-up period or stroke in the territory of the qualifying artery beyond 30 days). In the USA, the early publication already leads to strict limitations in the application of the Wingspan Stent (Stryker Neurovascular, Fremont, CA, USA). Among other criteria, two or more strokes despite aggressive medical management and a waiting period from most recent stroke of more than 7 days are required. In Europe, the balloon-expandable stents Pharos Vitesse (Codman \& Shurtleff, Raynham, Massachusetts, USA) and Channel (Balt, Montmorency, France) have been withdrawn from European markets last year, while Wingspan is still available. It is no surprise that some companies are not willing to take the risk to stay in an environment with strong opposing winds and limited chances of success. Intracranial stenting, by comparison, is an uncommon procedure representing a relatively small market in Western countries.

Our interests as physicians are necessarily congruent with the interests of our patients. Their interests are not respected when we consider an over-interpretation of 
the SAMMPRIS results. What do the data tell us for the treatment decision in the next patient? What question does SAMMPRIS answer exactly? Which hypothesis has been tested? Were the relevant patients enrolled? Was the relevant intervention deployed? Was the relevant comparator chosen, the relevant outcome measure used? Basically, the inclusion criteria required transitory ischemic attack or nonsevere stroke within 30 days of enrollment attributed to $>70 \%$ stenosis of a major intracranial artery. These criteria necessarily lead to a mixed patient cohort with a not more than average stroke risk in the natural course. There were no specifications on expected medical therapy before the index event, on pre-existing infarcts or the presence of hemodynamic lesions. These limitations impair the external validity of the SAMMPRIS data for patients that are typically endovascularly treated according to our experiences. Consequently, the authors of the joined opinion paper unanimously agreed that options need to be created for testing improved interventional methods in clinical studies.

We need to design and run studies in the field of Interventional Neuroradiology ourselves with a study design that we consider appropriate to answer the right questions. Otherwise, we cannot complain if trialists from neighboring disciplines will fill the gap that we leave open and just get the job done according to their terms. If you wish to test the hypothesis "Is therapy X beneficial for the specific subgroup of patients with the condition Y, if treated in selected centers by experienced interventionalists with specific material Z?" (Explanatory trial, Step A) you will design your trial differently than if you ask "Is therapy $\mathrm{X}$ beneficial for all patients in the country with a general condition $\mathrm{Y}$ and any material Z?" (Management trial, Step B). Both approaches are useful parts in the spectrum of studies, but much too often, Step B is done before step A. Basically, one could just enroll all patients in a management trial (Step B) primarily and then analyze subgroups representing the Step-A cohort. However, this is naïve, as it does not account for the oversimplification in the communication of trial results that follows any study. In fact, with this approach, you can effectively kill a certain therapy method. In that respect, medicine differs fundamentally from experimental physics where fully independent experiments can be conducted. In medicine, the result of a given study inadvertently influences conduct and interpretation of the next. The willingness of physicians for supporting patient recruitment is dependent on previous results.

We need to select patients who will have the biggest therapy benefit and lower the complication rate in the interventional arm. Patients with pre-existing infarcts in the territory of the affected artery and stroke as qualifying event while on antithrombotic treatment are typical in our clinical practice. In the final SAMMPRIS results, these patients had outcome events in $35 \%$ after best medical therapy and $33 \%$ after stenting [3], representing an absolute higher risk for poor outcome that is $20 \%$ higher in the medical group and $10 \%$ in the stenting group. These patients are outliers in the SAMMPRIS population but typical for our clinical practice. Such a high stroke rate is not an acceptable clinical course. Medical therapy is not efficacious enough in these high-risk patients. It would be promising to design a study focused on this patient group that is typical for our interventional practice. Lowering the complication rate in the interventional arm is also realistic, to a level, somewhere between SAMMPRIS observations, and the large body of self-reported data [4-6]. Based on these estimations and on the publication of the meticulously analyzed complications in the stent arm of SAMMPRIS [7], it seems safe to assume that the complication rate can be lowered to $7-12 \%$, in particular with further progress in patient selection, interventional technique, and periprocedural patient management. According to conservative assumptions, a study of approximately 650 patients would be needed to show superiority of stenting vs. medical therapy (power: 0.80 , alpha $=0.05$ ). Such a study volume is certainly quite ambitious but not entirely impossible. For the time being, however, I think conducting such a study is not realistic. We need to start with more modest plans for setting up standards, closely monitoring procedures and gathering realistic figures on complication rates in these patients.

Opinions on the role of intracranial stenting based on SAMMPRIS as well as comments on possible shortcomings of this study have been exchanged ad nauseam. Constantly reiterating them will not help our patients, the healthcare authorities, or us as a medical specialty. To paraphrase Karl Popper, It is time to take part in the scientific game again!

\section{References}

1. IQWiG. Intracranial stents: more strokes than with drug treatment alone. 2014. https://www.iqwig.de/en/press/press-releases/pressreleases/intracranial-stents-more-strokes-than-with-drug-treatment-alone.6349.html. Accessed 20 Oct 2014.

2. Chimowitz MI, Lynn MJ, Derdeyn CP, Turan TN, Fiorella D, Lane BF, Janis LS, Lutsep HL, Barnwell SL, Waters MF, Hoh BL, Hourihane JM, Levy EI, Alexandrov AV, Harrigan MR, Chiu D, Klucznik RP, Clark JM, McDougall CG, Johnson MD, Pride GL, Jr., Torbey MT, Zaidat OO, Rumboldt Z, Cloft HJ, SAMMPRIS Trial Investigators. Stenting versus aggressive medical therapy for intracranial arterial stenosis. N Engl J Med. 2011;365:993-1003.

3. Derdeyn CP, Chimowitz MI, Lynn MJ, Fiorella D, Turan TN, Janis LS, Montgomery J, Nizam A, Lane BF, Lutsep HL, Barnwell SL, Waters MF, Hoh BL, Hourihane JM, Levy EI, Alexandrov AV, Harrigan MR, Chiu D, Klucznik RP, Clark JM, McDougall CG, Johnson MD, Pride GL, Jr., Lynch JR, Zaidat OO, Rumboldt Z, Cloft HJ, Stenting and Aggressive Medical Management for Preventing Recurrent Stroke in Intracranial Stenosis Trial Investigators. Aggressive medical treatment with or without stenting in high-risk patients with intracranial artery stenosis (SAMMPRIS): the final results of a randomised trial. Lancet. 2014;383:333-41. 
4. Kurre W, Berkefeld J, Brassel F, Brüning R, Eckert B, Kamek S, Klein GE, Knauth M, Liebig T, Maskova J, Mucha D, NeumannHaefelin T, Pilgram-Pastor S, Sitzer M, Sonnberger M, Tietke M, Trenkler J, Turowski B, INTRASTENT Study Group. In-hospital complication rates after stent treatment of 388 symptomatic intracranial stenoses: results from the INTRASTENT multicentric registry. Stroke. 2010;41:494-8.

5. Farooq MU, Al-Ali F, Min J, Gorelick PB. Reviving intracranial angioplasty and stenting "SAMMPRIS and beyond". Front Neurol. 2014;5:101

6. von Schoenfeldt P, Krützelmann A, Bußmeyer M, Mpotsaris A, Rosenkranz M, Fiehler J, Weber W, Buhk JH. Elective treatment of intracranial stenosis with the balloon-expandable Pharos Vitesse stent: 30 -day stroke rate and complications. J Neurointerv Surg. 2014 Feb 7. doi:10.1136/neurintsurg-2013-011019. Epub ahead of print.
7. Derdeyn CP, Fiorella D, Lynn MJ, Rumboldt Z, Cloft HJ, Gibson D, Turan TN, Lane BF, Janis LS, Chimowitz MI, Stenting and Aggressive Medical Management for Preventing Recurrent Stroke in Intracranial Stenosis Trial Investigators. Mechanisms of stroke after intracranial angioplasty and stenting in the SAMMPRIS trial. Neurosurgery. 2013;72:777-95. 